\title{
Managing High Seas through a Sui Generis
}

\author{
Arif Havas Oegroseno
}

\section{Keywords}

marine biological diversity - areas beyond national jurisdiction - marine genetic resources - environment - Indonesia - conservation

One of the most challenging issues in ocean affairs today is managing marine genetic resources in the high seas. Discussions on biodiversity beyond national jurisdictions is complex and vast, encompassing fundamental questions such as the meaning of conservation and management of biodiversity, the meaning of marine genetic resources, transfer of technology, benefit sharing, the meaning and implication of a legally binding instrument, and many other rather complex matters. I shall not address all of them but offer some of my observations based on our geographic ocean features as the largest archipelagic State in the world.

Indonesia is a country that has direct contact with area of biodiversity beyond national jurisdiction in two fronts, namely in the eastern part of Indian Ocean and the western part of the Pacific Ocean. I am sure, Indonesia is not the only one that has these rather unique geographic features. Many of those countries are also represented at this Conference.

In our view, activities in the areas beyond national jurisdiction will have a direct impact on areas under our jurisdiction and also vice versa.

Conservation and management of living resources as well as pollution are of particular concern, because the marine environment as an ecosystem will affect them regardless of legal boundaries established in accordance with UNCLOS 1982. Fish have no passports.

Furthermore, Indonesia has delineated its continental shelf beyond 200 nautical miles in the northwest of Sumatra based on the recommendation adopted by the Commission on the Limits of the Continental Shelf of 28 March 2011, and recently, on 11 April 2019, Indonesia made another submission on the Eauripik Rise in the Pacific Ocean, covering an area of more than 196,000 square kilometers. 
In those areas, significant continental shelf is going to be within Indonesia's national jurisdiction while the water column is under the regime of the high seas. We have this experience in a different context with one of our neighboring countries, Australia. However, an overlap of our continental shelf with the water column of ввNJ would be a first.

This specific concern has to be addressed because it leaves a gaping question with regard to the legal status on the biodiversity and genetic resources in those related areas with two different regimes. There must be a clarity in this particular situation whereby the biodiversity or genetic resources in the water column may have their life cycle starting from the subsoil and seabed or the other way around, as well as biodiversity or genetic resources that do have uninterrupted and well-connected biological linkage between the seabed and the water column in areas where overlap between extended continental shelf and BBNJ exist.

The possible solution is to assign the water column above the seabed beyond 200 nautical miles that have been recommended by the Commission on Limits of the Continental Shelf to the coastal countries concerned. This may create fewer complications on the management of the biodiversity beyond national jurisdiction. The assignment may be followed with transparent monitoring by an international organ. However, some may consider this approach unfair because the coastal countries with extended continental shelves gain access to the resources in the water column. It is indeed an issue that has not been dealt with thoroughly at the intergovernmental conference (IGC) discussion in New York.

A specific arrangement, a suigeneris, may be considered in this unique overlapping situation of extended continental shelf and the water column above it which may be included as ABNJ.

In this geographic situation of direct boundary with ABNJ, an issue of pollution or side effects coming from economic activities in the ABNJ going into the Exclusive Economic Zone or continental shelf of a coastal nation, especially small archipelagic and island developing States, must also be taken into consideration. As a matter of fact, many small island developing countries have become the epicenter of marine biodiversity in the world.

Again, being directly connected to an ABNJ has certain complicated features, thus the issue of adjacency is critical to be discussed in the coming deliberations. The interests of all countries, especially the small island developing countries, that are adjacent to $\mathrm{ABNJ}$ require to be taken into account in the legally binding instrument on BBNJ.

A certain type of guarantee for enviromental protection of adjacent marine areas from any activity relates to exploration in $A B N J$ as well as the 
establishment of responsibility of any environmental damages indeed needs special discussion.

The adjacency factor must be considered thoroughly.

On the issue of what is marine genetic resources itself, what it and what it is not, Indonesia has wealth of experience on defining what is marine genetic resources in our vast waters stretching from the Indian Ocean to the South China Sea to the Pacific Ocean. For us, under our laws, regulations and culture, marine genetic resources include all life forms at sea whether they are part of an ecosystem such as coral reef systems or mangroves, or highly migratory fish, or part of economic activity or not. Furthermore, activities in ABNJ may also be threats to certain species of fish or corals or some other life forms.

Our understanding of oceanic and terrestrial biodiversity is similar; thus certain plants and herbs that are both important for our biodiversity but also have healing power so that they have economic value, the same as fish that have economic value as well as importance for biodiversity in our ocean. In the context of sustainable development, it is thus relevant to be able to strike the balance between conservation, the environment and economic benefit.

We are of course aware of the discussion on the monetary and nonmonetary values that are derived from the utilisation of marine genetic resources and how such benefits may be shared.

While not opposing the idea of sharing of monetary benefit, we are also aware of the degree of complication in addressing this issue. In our experience on anything related to monetary matters, things are going to be very complicated. Sometimes the technicalities will become hindrances and blockages to smooth monetary aspects of benefit sharing.

Therefore, it is better for us to focus on non-monetary benefit including a limitation of duration of any intellectual property rights derived from marine genetic resources in $\mathrm{ABNJ}$, as well as sharing knowledge such as in the form of scholarships or academic exchanges or strengthening the capacity of a particular party of a country or applying the already proven model under the auspices of International Seabed Authority.

Honored participants, although our planet Earth has more waters than lands, we do not have a single organization that deal with ocean. We have UNGA, ITLOS, ISBA, DOALOS, IMO, FAO, IOC, Regional Fisheries Organizations in many regions, and many others. Thus, I believe that the instrument of ABNJ should not be in conflict with the existing mechanisms as well as with other already existing international legal instruments on ocean affairs.

Reconciling interests between States with opposite views in ocean affairs is not an impossible task. We have seen how our predecessors created the archipelagic sea lane passage to balance the archipelagic States needs, the Exclusive 
Economic Zone which balances the interests of coastal States with user states in global navigation, and also the establishment of the Commission on the Limits of the Continental Shelf for delineation of the continental margin beyond 200 nautical miles in order to prevent abuse from a coastal State in its seabed claim. These are just a few of many balanced results of UNCLOS 1982.

I believe this 43rd COLP Annual Conference will meet its objective as an avenue to exchange views and ideas as well as pose some crucial questions that we should carefully consider in order to form the new instrument on BBNJ. I truly hope this conference and all of us will greatly contribute to the process in the IGC. 
Arif Havas Oegroseno - 9789004422438

Downloaded from Brill.com@4/26/2023 11:00:36AM via free access 